\title{
Hydrate Formation: Considering the Effects of Pressure, Temperature, Composition and Water
}

\author{
Jerome Rajnauth $^{[\mathrm{b}]^{*}}$; Maria Barrufet ${ }^{[\mathrm{b}]}$; Gioia Falcone ${ }^{[\mathrm{b}]}$
}

\footnotetext{
${ }^{[a]}$ Petroleum Company of Trinidad and Tobago (Petrotrin), Trinidad and Tobago. ${ }^{[b]}$ Petroleum Engineering, Texas A\&M University, College Station, Texas. *Corresponding author.
}

Received 12 June 2012; accepted 7 August 2012

\section{Abstract}

The main components in producing natural gas hydrate (whether for gas storage or for transportation), are water and natural gas, at low temperatures and high pressures. Each variable has a significant effect on the formation of gas hydrate. It is therefore critical to analyze the effect of each variable on hydrate formation to ascertain the best conditions required for a successful gas hydrate formation process.

This research evaluates the effect of these critical elements: Temperature, pressure, gas composition, and water upon gas hydrate formation. This paper summarizes the findings of a sensitivity analysis using varying natural gas compositions. Results show that the composition of the natural gas can affect the temperature and pressure required for formation of the hydrate. Even more significant is the effect of impurities in the natural gas on the pressure temperature (PT) curves of the hydrate. Carbon dioxide, hydrogen sulfide and nitrogen are the main impurities in natural gas affecting the hydrate formation. At a particular temperature, nitrogen increases the required hydrate formation pressure while both carbon dioxide and hydrogen sulfide lower the required hydrate formation pressure.

The quantity of water required for hydrate formation is an important variable in the process. The water to gas ratio vary depending on the composition of the natural gas and the pressure. Generally the mole ratio of water to natural gas is about 6:1; however, to achieve maximum hydrate formation an incremental increase in water or pressure may be required. This is an interesting trade-off between additional water and additional pressure in obtaining maximum volume of hydrate and is shown in this analysis.
Key words: Hydrate formation; Temperature; Pressure; Gas composition; Water

Rajnauth, J., Barrufet, M., \& Falcone, G. (2012). Hydrate Formation: Considering the Effects of Pressure, Temperature, Composition and Water. Energy Science and Technology, 4(1), 60-67. Available from: URL: http://www.cscanada.net/index. $\mathrm{php/est/article/view/10.3968/j.est.1923847920120401.397}$ DOI: http://dx.doi.org/10.3968/j.est.1923847920120401.397

\section{INTRODUCTION}

Natural gas hydrates are ice-like crystalline solids formed from a mixture of water and natural gas subjected to high pressure and suitable low-temperature conditions. These conditions are found in the permafrost and under the ocean floor. Hydrates consist of geometric lattices of water molecules containing cavities occupied by light hydrocarbons and other types of gaseous components for such as nitrogen, carbon dioxide, and hydrogen sulfide. Transporting gas in the form of a gas hydrate may prove to be very useful in capturing stranded natural gas to meet future small scale energy demand. Gas hydrate can provide an easier to produce, safer and cheaper to store method of capturing natural gas when compared to other transportation modes such as CNG and LNG. This may be a promising and attractive method of gas transportation. Gas hydrate has a high gas to solid ratio. $1 \mathrm{ft}^{3}$ of hydrate contains 150-180 $\mathrm{ft}^{3}$ of gas per $\mathrm{ft}^{3}$ of water.

The objective of this work was to pre-design a system for transporting natural gas in hydrate form. As such a sensitivity analysis was used to investigate theoretically predicted hydrate formation PT boundaries from a thermodynamic model using a commercial simulator. The theoretical model was validated with selected data (Figure 1) to ensure that the predictions were reasonable.

In this analysis, twenty one natural gas compositions of typical wells mainly from Trinidad (Ministry of Energy, 
2007) are analyzed in order to estimate the process conditions to convert and transport $5 \mathrm{MMscf} / \mathrm{d}$ of gas in hydrate state to neighboring islands (e.g.). The natural gas streams obtained from these wells were, generally, sweet gases (without $\mathrm{H}_{2} \mathrm{~S}$ ) and ranges in composition from $\mathrm{C}_{1}$ to $\mathrm{C}_{10}$. These samples are shown in Table 2. The most important design variables affecting the percentage of hydrate formed include: pressure, temperature, composition, and amount of water required to form hydrate.

Previous research work in this area included simple laboratory experiments and small scale pilot projects for hydrate formation using simple gases such as methane.
Hence, it is important to determine the operational conditions, quantities and design variables for designing the gas hydrate formation for an upscale process. Gudmundsson et al. (1994) deduced from their laboratory experiments that the conditions required for formation of the hydrate are 290 to 870 psia and 32 to $68{ }^{\circ} \mathrm{F}$. This experiment was conducted using methane another study (Gudmundsson et al., 1998) looked at two gas samples; pure methane and a mixed gas sample $\left(92 \% \mathrm{C}_{1}, 5 \% \mathrm{C}_{2}\right.$, and $3 \% \mathrm{C}_{3}$ ). Most of the previous studies focused on simple gases with composition of primarily methane and ethane to form gas hydrate Table 1 .

Table 1

Summary of Previous Studies

\begin{tabular}{lcc}
\hline \multicolumn{1}{c}{ Country } & Studies & Sample used in study \\
\hline UK & Advantica (Since 1996) & Methane Gas \\
Norway & NTNU (Since 1990) & Methane sample and Mix sample of 92\% methane, 5\% ethane and 3\% propane \\
Japan & Mitsui Engineering (Since 2001) & Methane Gas \\
\hline
\end{tabular}

The composition of natural gas has significantly more components than methane and ethane and this analysis uses twenty natural gas samples. This analysis shows how the composition can have significant impact on the formation of the hydrate. Results show that the composition of the natural gas can affect the temperature and pressure required for formation of the hydrate. The composition of the sample also affects the water to gas mole ratio and hence the amount of water required for hydrate formation.

The composition of the natural gas is an important factor when considering the temperature and pressure range to form natural gas hydrates. The formation conditions of $600 \mathrm{psia}$ and $35^{\circ} \mathrm{F}$ were then chosen as it represents potential upscaling conditions deduced from experimental studies conducted by Okutani et $a l, 2007$. Mole and volume $\%$ of hydrate formed are shown. Another important feature of hydrates is its high storage capacity. Gas of 180 (volume of gas at standard conditions) / (volume of hydrates) can potentially be packed into gas hydrate crystal. This analysis would also look at how storage capacity of hydrate is affected by temperature and pressure.

Table 2

Natural Gas Composition / Mole \%

\begin{tabular}{|c|c|c|c|c|c|c|c|c|c|c|c|}
\hline Sample & & 1 & 2 & 3 & 4 & 5 & 6 & 7 & 8 & 9 & 10 \\
\hline Nitrogen & $\mathrm{N}_{2}$ & 0.56 & 0.78 & 3.93 & 0.87 & 1.32 & 2.40 & 0.60 & 2.21 & 1.09 & 2.55 \\
\hline Hydrogen Sulphide & $\mathrm{H}_{2} \mathrm{~S}$ & 0.00 & 0.00 & 0.00 & 0.00 & 0.00 & 0.00 & 0.00 & 0.00 & 0.00 & 0.00 \\
\hline Carbon Dioxide & $\mathrm{CO}_{2}$ & 3.92 & 2.84 & 2.98 & 3.75 & 0.90 & 0.64 & 3.64 & 1.12 & 1.73 & 0.44 \\
\hline Methane & $\mathrm{C}_{1}$ & 92.09 & 92.04 & 88.29 & 87.77 & 88.02 & 88.37 & 87.48 & 86.21 & 85.20 & 85.04 \\
\hline Ethane & $\mathrm{C}_{2}$ & 2.52 & 2.82 & 3.05 & 4.86 & 6.60 & 5.03 & 4.85 & 6.47 & 6.76 & 7.00 \\
\hline Propane & $\mathrm{C}_{3}$ & 0.51 & 0.74 & 0.65 & 1.51 & 1.63 & 1.77 & 1.91 & 2.32 & 2.73 & 3.23 \\
\hline Isobutane & $\mathrm{iC}_{4}$ & 0.10 & 0.14 & 0.24 & 0.31 & 0.20 & 0.65 & 0.34 & 0.44 & 0.36 & 0.32 \\
\hline N-Butane & $\mathrm{nC}_{4}$ & 0.12 & 0.21 & 0.30 & 0.41 & 0.55 & 0.49 & 0.54 & 0.65 & 1.00 & 0.82 \\
\hline Isopentane & $\mathrm{iC}_{5}$ & 0.05 & 0.10 & 0.14 & 0.19 & 0.17 & 0.20 & 0.21 & 0.25 & 0.30 & 0.16 \\
\hline N-Pentane & $\mathrm{nC}_{5}$ & 0.04 & 0.08 & 0.14 & 0.12 & 0.21 & 0.15 & 0.16 & 0.18 & 0.38 & 0.20 \\
\hline Hexanes plus & $\mathrm{C}_{6+}$ & 0.09 & 0.25 & 0.28 & 0.21 & 0.40 & 0.30 & 0.27 & 0.15 & 0.45 & 0.24 \\
\hline Heptanes & $\mathrm{C}_{7}$ & 0.00 & 0.00 & 0.00 & 0.00 & 0.00 & 0.00 & 0.00 & 0.00 & 0.00 & 0.00 \\
\hline Octanes & $\mathrm{C}_{8}$ & 0.00 & 0.00 & 0.00 & 0.00 & 0.00 & 0.00 & 0.00 & 0.00 & 0.00 & 0.00 \\
\hline Nonanes & $\mathrm{C}_{9}$ & 0.00 & 0.00 & 0.00 & 0.00 & 0.00 & 0.00 & 0.00 & 0.00 & 0.00 & 0.00 \\
\hline Decanes + & $\mathrm{C}_{10}^{+}$ & 0.00 & 0.00 & 0.00 & 0.00 & 0.00 & 0.00 & 0.00 & 0.00 & 0.00 & 0.00 \\
\hline
\end{tabular}

To be continued 
Continued

\begin{tabular}{lccccccccccc}
\hline \multicolumn{1}{c}{ Sample } & & $\mathbf{1 1}$ & $\mathbf{1 2}$ & $\mathbf{1 3}$ & $\mathbf{1 4}$ & $\mathbf{1 5}$ & $\mathbf{1 6}$ & $\mathbf{1 7}$ & $\mathbf{1 8}$ & $\mathbf{1 9}$ & $\mathbf{2 0}$ \\
\hline Sample & $\mathrm{N}_{2}$ & 0.46 & 1.09 & 0.49 & 0.06 & 0.09 & 0.09 & 0.09 & 0.21 & 0.05 & 0.00 \\
Nitrogen & $\mathrm{H}_{2} \mathrm{~S}$ & 0.00 & 0.00 & 0.00 & 0.00 & 0.00 & 0.00 & 0.00 & 0.00 & 0.00 & 0.00 \\
Carbon Dioxide & $\mathrm{CO}_{2}$ & 6.11 & 1.73 & 5.84 & 0.10 & 0.31 & 0.58 & 0.68 & 0.94 & 0.02 & 0.00 \\
Methane & $\mathrm{C}_{1}$ & 77.25 & 85.20 & 78.07 & 96.82 & 93.42 & 91.65 & 89.55 & 94.70 & 99.63 & 99.00 \\
Ethane & $\mathrm{C}_{2}$ & 8.77 & 6.76 & 8.96 & 1.75 & 2.96 & 3.48 & 4.14 & 2.90 & 0.17 & 1.00 \\
Propane & $\mathrm{C}_{3}$ & 3.35 & 2.73 & 3.34 & 0.64 & 1.15 & 1.31 & 1.83 & 0.74 & 0.03 & 0.00 \\
Isobutane & $\mathrm{iC}_{4}$ & 0.75 & 0.36 & 0.71 & 0.18 & 0.34 & 0.30 & 0.63 & 0.15 & 0.01 & 0.00 \\
N-Butane & $\mathrm{nC}_{4}$ & 1.32 & 1.00 & 1.21 & 0.19 & 0.33 & 0.39 & 0.93 & 0.17 & 0.02 & 0.00 \\
Isopentane & $\mathrm{iC}_{5}$ & 0.44 & 0.30 & 0.35 & 0.08 & 0.15 & 0.16 & 0.53 & 0.06 & 0.01 & 0.00 \\
N-pentane & $\mathrm{nC}_{5}$ & 0.69 & 0.38 & 0.50 & 0.06 & 0.11 & 0.16 & 0.47 & 0.05 & 0.02 & 0.00 \\
Hexanes plus & $\mathrm{C}_{6+}$ & 0.86 & 0.45 & 0.53 & 0.00 & 0.00 & 0.00 & 0.00 & 0.00 & 0.00 & 0.00 \\
Hexanes & $\mathrm{C}_{6}$ & 0.00 & 0.00 & 0.00 & 0.05 & 0.16 & 0.22 & 0.53 & 0.04 & 0.02 & 0.00 \\
Heptanes & $\mathrm{C}_{7}$ & 0.00 & 0.00 & 0.00 & 0.04 & 0.25 & 0.28 & 0.38 & 0.02 & 0.00 & 0.00 \\
Octanes & $\mathrm{C}_{8}$ & 0.00 & 0.00 & 0.00 & 0.02 & 0.18 & 0.39 & 0.18 & 0.02 & 0.00 & 0.00 \\
Nonanes & $\mathrm{C}_{9}$ & 0.00 & 0.00 & 0.00 & 0.01 & 0.16 & 0.23 & 0.05 & 0.00 & 0.00 & 0.00 \\
Decanes+ & $\mathrm{C}_{10}{ }^{+}$ & 0.00 & 0.00 & 0.00 & 0.00 & 0.76 & 0.76 & 0.01 & 0.00 & 0.02 & 0.00 \\
\hline
\end{tabular}

\section{METHODOLOGY}

The PVTSim program (Calsep, 2008) was used to estimate the conditions at which gas hydrates may form and in what quantities. Hydrates are formed when the hydrate state is energetically favorable as compared to a pure water state (fluid water or ice).

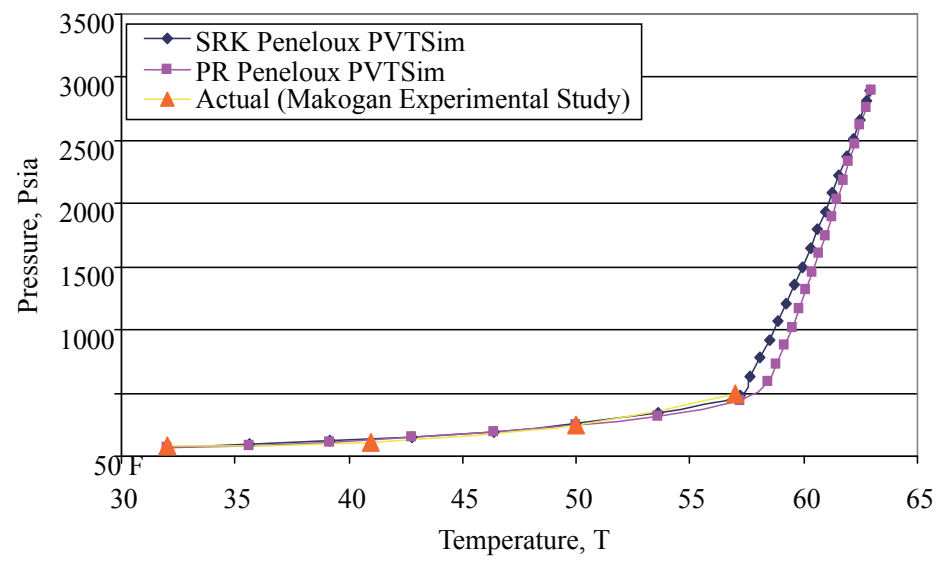

Figure 1

Comparison of the Models Used in PVTSim with Actual Experimental Data

Figure 1 above compares the two models used with PVTSim software with actual data from Makogan Experimental study (Makogan, 1985) for ethane hydrate. The actual data matches closely with the Soave Redlich Kwong model and Peng Robinson model. This validates the theoretical model and ensures reasonable predictions.

The following is some of the steps used in this sensitivity analysis

(1) Inputted 21 gas compositions in PVTSim program and generate pressure/temperature data points.

(2) Plotted PT curves for all samples.

(3) Selected samples with lowest and highest PT curves. (Sample 11 and Sample Dry Gas)

(4) Selected range of temperatures and pressures for analyzing both samples for different mole ratios. Ranges selected above PT curve.

(5) Used output from program to evaluate mole \% of hydrate formed, volume $\%$, amount of gas stored in $1 \mathrm{ft}^{3}$, amount of water required and effect of composition on hydrate formation conditions.

\section{RESULTS AND DISCUSSION}

The molar concentrations of the natural gas analyzed are shown in Table 2. It was observed that they have carbon dioxide concentrations varying from $0.44 \mathrm{~mol} \%$ (Sample 10) to $6.11 \mathrm{~mol} \%$ (Sample 11), $\mathrm{C}_{1}$ concentration varying from $85.04 \mathrm{~mol} \%$ (Sample 8) to $99.63 \mathrm{~mol} \%$ (Sample 
20) and a $\left(\mathrm{C}_{2}+\mathrm{C}_{3}+\mathrm{iC}_{4}+\mathrm{nC}_{4}+\mathrm{iC}_{4}+\mathrm{nC}_{5}+\mathrm{iC}_{5}+\mathrm{C}_{6+}\right)$ composition, varying from $1.0 \mathrm{~mol} \%$ (Dry Gas) to 16.18 mol \% (Sample 11).

\subsection{Natural Gas Hydrate Forming Conditions}

The hydrate forming temperature/pressure data points for the twenty one natural gas compositions were generated. However, only the samples with the highest and lowest PT curves are shown in Figure 2. The PT profiles of all other samples fall between these two extremes.

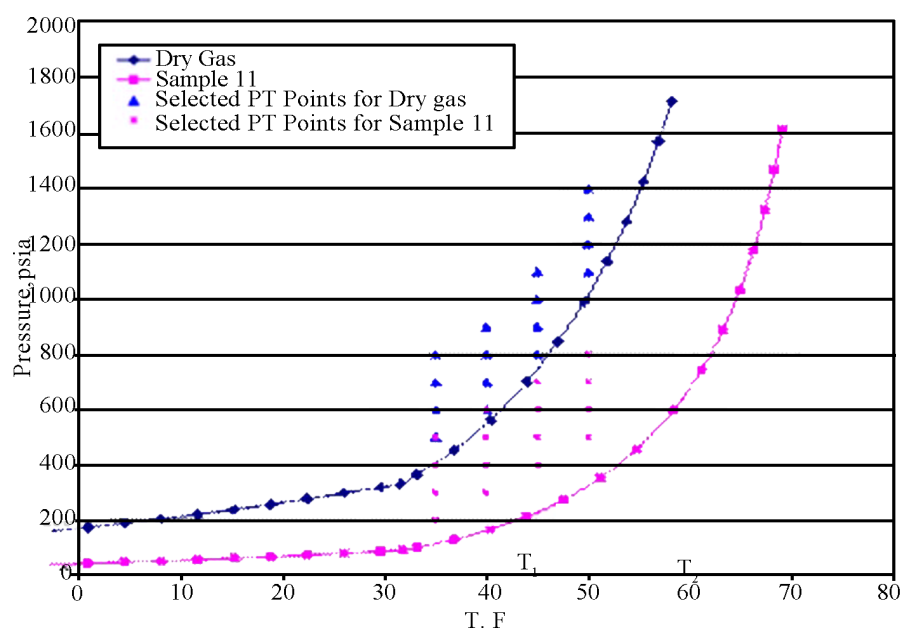

Figure 2

Hydrate Forming Temperature / Pressure (Equilibrium Curves) of Sample 11 and Dry Gas Sample

The uppermost curve corresponds to the natural gas obtained from sample Dry Gas while the lowermost curve corresponds to the natural gas obtained from the Sample 11. At a fixed pressure, i.e. 600 psi sample 11 will form hydrates if the temperature is lower than $T_{2}$, while sample dry gas will form hydrate if $\mathrm{T}$ is lower than $\mathrm{T}_{1}$. It was also observed that at a fixed temperature, the higher methane content (Dry Gas) in the natural gas increases the pressure of hydrate formation. Similarly, the higher propane concentrations in the sample (Samples 11) lower the formation pressure of the hydrate at a fixed temperature.

\subsection{Effect of Composition}

Figure 3 shows the effect of the light components $\left(\mathrm{N}_{2}+\right.$ $\mathrm{CO}_{2}+\mathrm{C}_{1}$ ) on hydrate formation pressures at temperatures of $40{ }^{\circ} \mathrm{F}, 45^{\circ} \mathrm{F}$ and $50^{\circ} \mathrm{F}$. The points, in Figure 3, correspond to the natural gas streams given in Table 2. It is observed that as the $\left(\mathrm{N}_{2}+\mathrm{CO}_{2}+\mathrm{C}_{1}\right)$ composition varied from $84 \mathrm{~mol} \%$ to $99 \mathrm{~mol} \%$, the hydrate formation pressure increases from $161.5 \mathrm{psi}$ to $572.1 \mathrm{psi}$ at $40^{\circ} \mathrm{F}$. Similar trends can be seen at the temperatures $45^{\circ} \mathrm{F}$ and $50^{\circ} \mathrm{F}$.

\section{Figure 3}

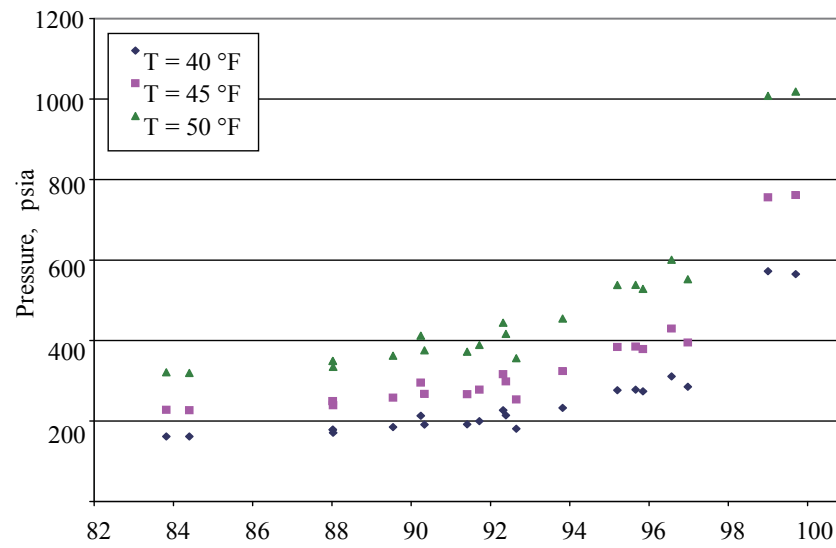

Hydrate Formation Pressure for Different $\left(\mathrm{N}_{2}+\mathrm{CO}_{2}+\mathrm{C}_{1}\right)$ Compositions from the 21 Samples

The influence of the heavier is opposite to that observed in Figure 3, i.e., varying $\left(\mathrm{C}_{2}+\mathrm{C}_{3}+\mathrm{iC}_{4}+\mathrm{nC}_{4}\right.$ $\left.+\mathrm{iC}_{5}+\mathrm{nC}_{5}+\mathrm{C}_{6+}\right)$ concentration from $0.3 \mathrm{~mol} \%$ to 16.2 mol\%, the hydrate formation pressure decreases from 565.2 psi to 161.4 psi approximately, at $40^{\circ} \mathrm{F}$. 


\subsection{Further Analysis Using Two Selected Samples}

From the twenty one samples two samples were selected for further analysis. These samples are Sample 11 and Sample Dry Gas as seen in Figure 2. Composition of Sample 11 and Sample Dry Gas are shown in Table 2. A range of temperatures and pressures above the equilibrium line were selected for analysis of the two selected samples using a water-gas mole ratio from 1:1 to $6: 1$. These ranges are also illustrated in Figure 2 and were selected to identify PT points above the equilibrium line resulting in $100 \%$ hydrate formation and to evaluate a hydration formation trend as PT changes. For each of the temperatures selected four 100 psia increment pressure points were chosen above the equilibrium line. The effect of water content on hydrate formation and pressure and temperature effects on storage capacity are shown.

\subsubsection{Effect of Water Content on Volume of Hydrate}

\section{Formed}

The effect of the water content on volume of hydrate formed was simulated at $40^{\circ} \mathrm{F}, 45^{\circ} \mathrm{F}$ and $50{ }^{\circ} \mathrm{F}$ and at pressures varying from 300 psi to 800 psi for Sample 11 and 600 psia to 1400 psia for Sample Dry Gas. This effect was analyzed considering the following levels of the mol water phase/mol feed ratio, 1:1, 2:1, 3:1, 4:1, 5:1 and 6:1. Numerical examples of this analysis are given in Table 3 for the Sample 11, which has the lower $\left(\mathrm{N}_{2}+\mathrm{CO}_{2}+\mathrm{C}_{1}\right)$ natural gas composition and in Table 4 for the Sample Dry gas, which has the higher $\left(\mathrm{N}_{2}+\mathrm{CO}_{2}+\mathrm{C}_{1}\right)$ natural gas composition. Tables 3 and 4 show the $\mathrm{V}_{\mathrm{GAS}} /\left(\mathrm{V}_{\mathrm{GAS}}+\mathrm{V}_{\mathrm{HYD}}\right)$ ratio as a function of temperature, pressure and mol water phase/mol feed ratio. $\mathrm{V}_{\mathrm{GAS}}$ represents the volume of gas at the particular temperature and pressure specified in the table cell. $\mathrm{V}_{\mathrm{HYD}}$ represent volume of hydrate with gas at standard condition. $\mathrm{A} \mathrm{V}_{\mathrm{GAS}} /\left(\mathrm{V}_{\mathrm{GAS}}+\mathrm{V}_{\mathrm{HYD}}\right)$ ratio of 0.444 indicates $44.4 \%$ of free gas at a particular temperature and pressure to be captured in hydrate formed. The empty cells to the left of the data in the table correspond to PT points very close to or below the equilibrium line. The empty cells to the right correspond to PT points not chosen for the sample as they correspond to point's way above the equilibrium line.

Table 3

Effect of Water Content on Volume of Hydrate Formed (Sample 11)

\begin{tabular}{|c|c|c|c|c|c|c|c|}
\hline \multirow{3}{*}{$\begin{array}{c}\mathbf{T} \\
\left({ }^{\mathrm{O}} \mathbf{F}\right)\end{array}$} & \multirow{3}{*}{$\begin{array}{l}\text { Mole } \\
\text { Ratio }\end{array}$} & \multicolumn{6}{|c|}{ Pressure, psia } \\
\hline & & 300 & 400 & 500 & 600 & 700 & 800 \\
\hline & & \multicolumn{6}{|c|}{ V gas/ (Vgas+Vhyd) } \\
\hline \multirow{6}{*}{40} & 1 & 0.974 & 0.965 & 0.955 & 0.946 & & \\
\hline & 2 & 0.940 & 0.919 & 0.897 & 0.875 & & \\
\hline & 3 & 0.931 & 0.854 & 0.817 & 0.782 & & \\
\hline & 4 & 0.987 & 0.750 & 0.699 & 0.647 & & \\
\hline & 5 & 0.850 & 0.710 & 0.505 & 0.435 & & \\
\hline & 6 & 0.830 & 0.809 & 0.134 & 0.054 & & \\
\hline \multirow{6}{*}{45} & 1 & & 0.965 & 0.956 & 0.946 & 0.935 & \\
\hline & 2 & & 0.920 & 0.899 & 0.877 & 0.856 & \\
\hline & 3 & & 0.870 & 0.821 & 0.786 & 0.752 & \\
\hline & 4 & & 0.840 & 0.730 & 0.655 & 0.607 & \\
\hline & 5 & & 0.810 & 0.690 & 0.450 & 0.391 & \\
\hline & 6 & & 0.780 & 0.650 & 0.420 & 0.095 & \\
\hline \multirow{6}{*}{50} & 1 & & & 0.957 & 0.946 & 0.937 & 0.926 \\
\hline & 2 & & & 0.900 & 0.880 & 0.859 & 0.837 \\
\hline & 3 & & & 0.850 & 0.780 & 0.757 & 0.725 \\
\hline & 4 & & & 0.820 & 0.730 & 0.620 & 0.573 \\
\hline & 5 & & & 0.780 & 0.700 & 0.570 & 0.370 \\
\hline & 6 & & & 0.750 & 0.660 & 0.531 & 0.331 \\
\hline
\end{tabular}

Table 4

Effect of Water Content on Volume of Hydrate Formed (Sample Dry Gas)

\begin{tabular}{|c|c|c|c|c|c|c|c|c|c|c|}
\hline \multirow{3}{*}{$\begin{array}{c}\mathbf{T} \\
{ }^{\mathrm{o}} \mathbf{F}\end{array}$} & \multirow{3}{*}{ Mole Ratio } & \multicolumn{9}{|c|}{ Pressure, psia } \\
\hline & & 600 & 700 & 800 & 900 & 1000 & 1100 & 1200 & 1300 & 1400 \\
\hline & & \multicolumn{9}{|c|}{ V gas/ (Vgas+Vhyd) } \\
\hline \multirow{6}{*}{40} & 1 & 0.9497 & 0.9408 & 0.9318 & 0.9228 & & & & & \\
\hline & 2 & 0.8847 & 0.8657 & 0.8469 & 0.8284 & & & & & \\
\hline & 3 & 0.7974 & 0.767 & 0.738 & 0.7103 & & & & & \\
\hline & 4 & 0.6741 & 0.6319 & 0.5933 & 0.5581 & & & & & \\
\hline & 5 & 0.4866 & 0.4352 & 0.3917 & 0.3546 & & & & & \\
\hline & 6 & 0.1669 & 0.1227 & 0.0912 & 0.0684 & & & & & \\
\hline \multirow{6}{*}{45} & 1 & & & 0.9329 & 0.924 & 0.9151 & 0.9062 & & & \\
\hline & 2 & & & 0.8491 & 0.831 & 0.8132 & 0.7958 & & & \\
\hline & 3 & & & 0.7418 & 0.7144 & 0.6884 & 0.6637 & & & \\
\hline & 4 & & & 0.5989 & 0.5639 & 0.532 & 0.5028 & & & \\
\hline & 5 & & & 0.3996 & 0.3622 & 0.3301 & 0.3024 & & & \\
\hline & 6 & & & 0.1021 & 0.0778 & 0.0596 & 0.0460 & & & \\
\hline \multirow{6}{*}{50} & 1 & & & & & & 0.9077 & 0.899 & 0.8904 & 0.8818 \\
\hline & 2 & & & & & & 0.7988 & 0.7822 & 0.7659 & 0.7502 \\
\hline & 3 & & & & & & 0.6683 & 0.6451 & 0.6232 & 0.6025 \\
\hline & 4 & & & & & & 0.5088 & 0.4821 & 0.4578 & 0.4355 \\
\hline & 5 & & & & & & 0.3094 & 0.285 & 0.2638 & 0.2451 \\
\hline & 6 & & & & & & 0.0532 & 0.0418 & 0.0329 & 0.0259 \\
\hline
\end{tabular}


From Tables 3 and 4, it can be observed that the $\mathrm{V}_{\mathrm{GAS}} /$ $\left(\mathrm{V}_{\mathrm{GAS}}+\mathrm{V}_{\mathrm{HYD}}\right)$ ratio decreases by (1) increasing the water content at fixed temperature and pressure and (2) increasing the pressure at fixed temperature and mole ratio. This means that the volume of hydrate formed increases when the pressure and water content increases. For a fixed $\mathrm{P}$ and $\mathrm{T}$ the volume of hydrate reaches a maximum as the moles of water increases. Beyond that further additions of water will result in free water liquid phase. For a fixed mole ratio the volume of gas decreases due to compressibility effect.

\subsubsection{Effect of Pressure and Temperature on Storage Capacity of the Hydrate}

The storage capacity of hydrates makes them attractive for gas transportation. Hydrates have a high gas to solid ratio of 150-180 scf in 1cf (Masoudi et al., 2005). The volumetric content of gas in the hydrate state depends on the composition and density (Makogon et al., 2002).

\subsubsection{Sample 11 Analysis}

Figure 4 shows increasing pressure results in an increase in storage capacity of the hydrate at the selected pressures and temperatures shown in Figure 1 and a mole ratio of $6: 1$ (gives the best results). It can be seen for $40{ }^{\circ} \mathrm{F}$, storage capacity increases from $153 \mathrm{scf}$ in $1 \mathrm{cf}$ to $163 \mathrm{scf}$ in $1 \mathrm{cf}$ as pressure increases from 300 psia to 600 psia.

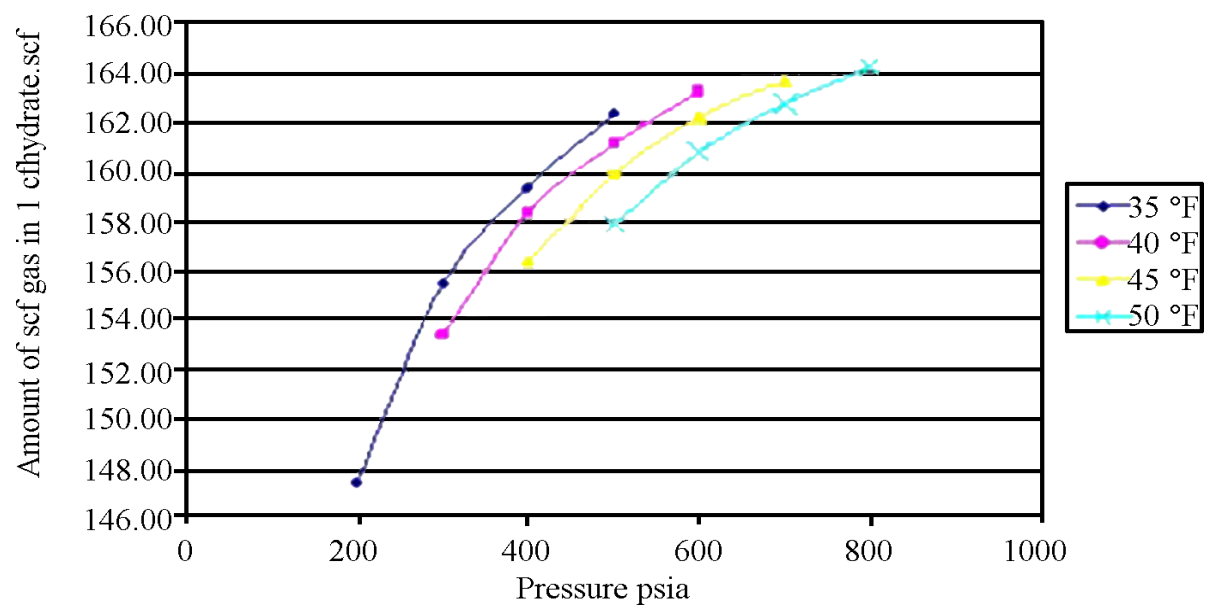

Figure 4

Effect of Temperature and Pressure on Storage Capacity of Hydrate with 6:1 Mole Ratio (Sample 11)

\subsubsection{Sample Dry Gas Analysis}

Figure 5 shows increasing pressure results in an increase in storage capacity of the hydrate at $35,40,45$ and $50^{\circ} \mathrm{F}$.
It can be seen for $40^{\circ} \mathrm{F}$, storage capacity increases from $166.8 \mathrm{scf}$ in $1 \mathrm{cf}$ to $170.2 \mathrm{scf}$ in $1 \mathrm{cf}$ as pressure increases from 600 psia to 900 psia.

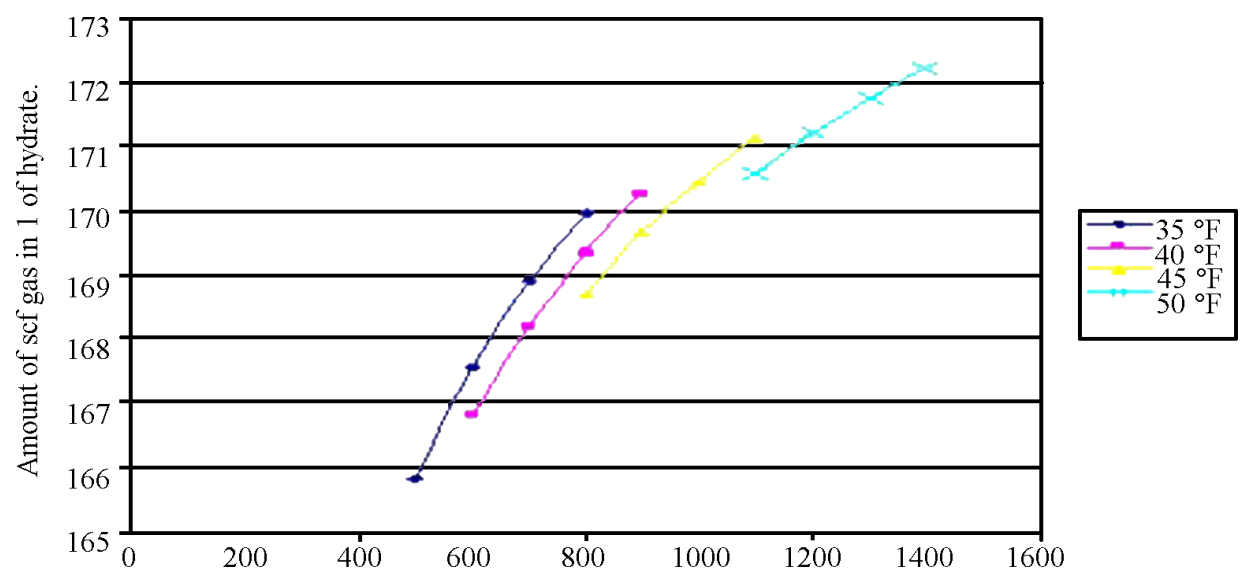

Figure 5

Effect of Temperature and Pressure on Storage Capacity of Hydrate with 6:1 Mole Ratio (Dry Gas)

\subsubsection{Mole \% of Hydrate Formed}

Figure 6 shows the maximum mole \% of hydrate formed for different mole ratio (water to gas) for 600 psia and 35

${ }^{\circ} \mathrm{F}$ for the dry gas sample. 


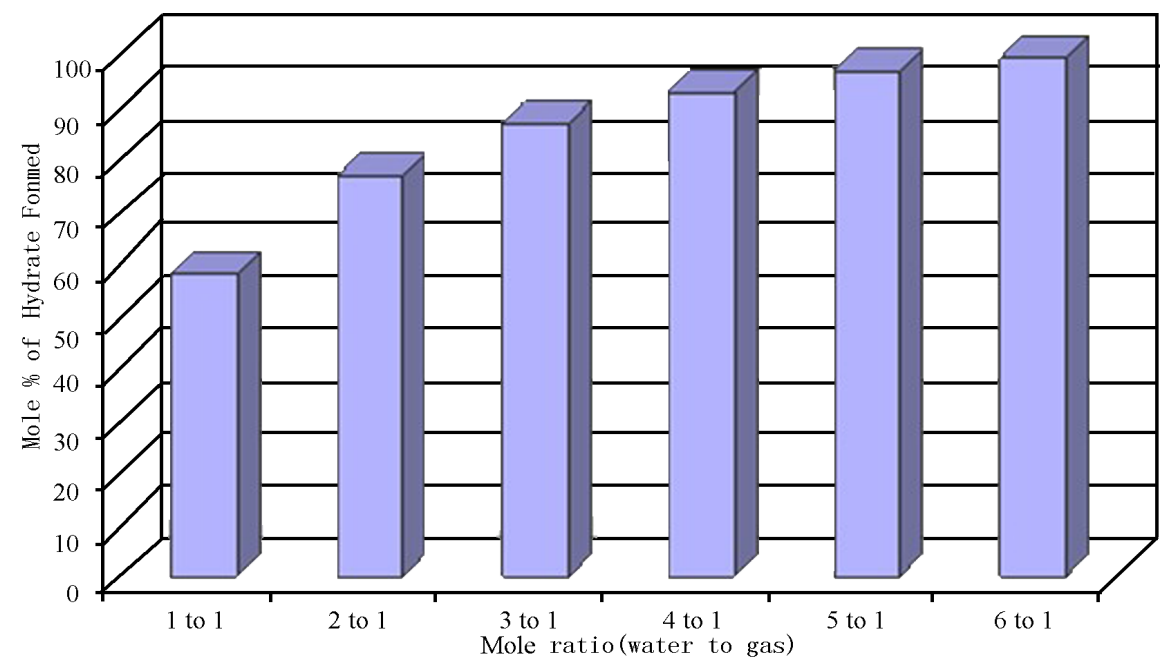

Figure 6

Maximum Mole \% of Hydrate Formed for Different Mole Ratios

Mole ratio of $6: 1$ gives the best results about $99.5 \%$ while a mole ratio of $1: 1$ gives about $58 \%$. A similar mole $\%$ trend is seen for Sample 11.

\subsubsection{Volume \% of Hydrate Formed}

Figure 7 shows the maximum volume $\%$ of hydrate formed for different mole ratio (water to gas) for 600 psia and $35^{\circ} \mathrm{F}$ for the dry gas sample.

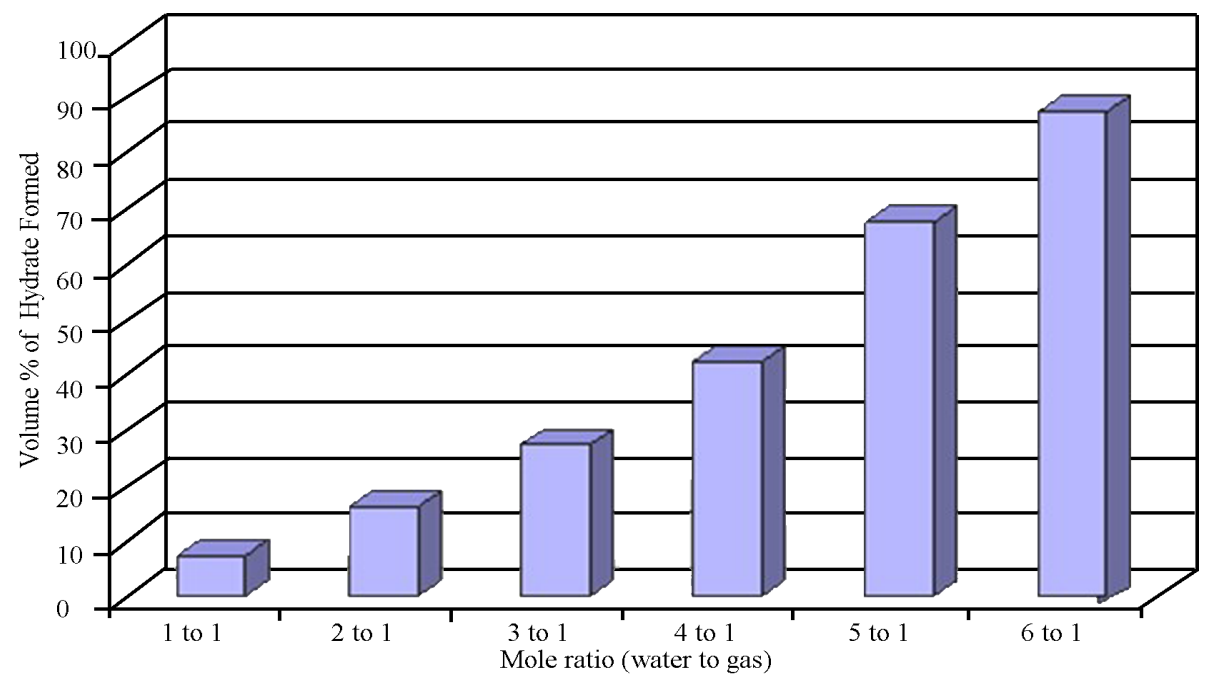

Figure 7

Maximum Volume \% of Hydrate Formed for Different Mole Ratios

Mole ratio of $6: 1$ give the best results about $87.4 \%$ while a mole ratio of $1: 1$ give about $7.3 \%$. The results show that even if 99.5 mole $\%$ of hydrate is formed only 87.4 volume \% of hydrate is formed. The remaining $12.6 \%$ represent free gas to be captured in hydrate form. This can be done by increasing mole ratio or increasing pressure. The free gas can be captured by additional water or by increasing the pressure which increases the storage capacity of the hydrate. An illustration of this will be shown below. A similar trend was seen for Sample 11 with 94.53 volume $\%$ of hydrate formed at 600 psia and $35^{\circ} \mathrm{F}$. It is therefore necessary to obtain $100 \%$ volume of sample
11 hydrates to transport to potential market. The initial conditions were $35^{\circ} \mathrm{F}, 600$ psia and $6: 1$ mole ratio and 94.53 volume $\%$ of hydrate formed.

Options available to increase the volume \% from $94.53 \%$ to $100 \%$ hydrate for sample 11 .

Increase in pressure above 600 psia is shown in table 5. The storage capacity at $600 \mathrm{psia}$ and $35^{\circ} \mathrm{F}$ was $165 \mathrm{scf}$ in $1 \mathrm{cf}$ of hydrate and increased to $167 \mathrm{scf}$ in $1 \mathrm{cf}$ with an additional 119 psia.

Increase in water to gas ratio above 6:1 ensures additional water to capture free gas. This is shown in Table 6 and an additional $68 \mathrm{bbls} / \mathrm{d}$ for 5 MMSCF/D. 
Table 5

Summary of Additional Increase in Pressure to Reduced Unreacted Gas from 5.43\%

\begin{tabular}{lcccccc}
\hline $\begin{array}{l}\text { Increase pressure above 600, } \\
\text { psia }\end{array}$ & $\mathbf{0}$ & $\mathbf{1 0 0}$ & $\mathbf{1 1 0}$ & $\mathbf{1 1 6}$ & $\mathbf{1 1 9}$ \\
\hline \begin{tabular}{l} 
Volume of unreacted gas, \% \\
\hline
\end{tabular} & 5.43 & 0.75 & 0.4 & 0.2 & 0.0 \\
\hline
\end{tabular}

Table 6

Summary of Additional Increase in Mole Ratio to Reduced Unreacted Gas from 5.43\%

\begin{tabular}{lcccccc}
\hline Increase in mole ratio above 6 & $\mathbf{0 . 0 0}$ & $\mathbf{0 . 0 5}$ & $\mathbf{0 . 0 8}$ & $\mathbf{0 . 0 9}$ & $\mathbf{0 . 1}$ \\
\hline Volume of unreacted gas, \% & 5.43 & 2.75 & 1.0 & 0.5 & 0.0 \\
Additional water required, bbls/d & 0.0 & 33 & 54 & 61 & 68 \\
\hline
\end{tabular}

Table 7 summarizes the comparison increasing mole ratios and pressures to obtain 100 volume $\%$ of hydrate formed for sample 11. There is a tradeoff between addition water and increasing pressure. In this case, it was a compromise between an additional 119 psia and $68 \mathrm{bbls} /$ $\mathrm{d}$ of water for transporting $5 \mathrm{MMSCF} / \mathrm{D}$.

Table 7

Varying Mole Ratio and Pressure for Sample 11 to Obtain $100 \%$ Volume of Hydrate

\begin{tabular}{lcc}
\hline & $\begin{array}{c}\text { Increasing } \\
\text { mole ratio }\end{array}$ & $\begin{array}{c}\text { Increasing } \\
\text { pressure }\end{array}$ \\
\hline Temperature, ${ }^{\circ} \mathrm{F}$ & 35 & 35 \\
Pressure, psia & 600 & 719 \\
Mole ratio, water & 6.1 & 6.0 \\
Additional water, bbls/d for 5,000 M SCF/ & 68 & 0 \\
day & 0 & 119 \\
Additional pressure, psia & \\
\hline
\end{tabular}

\subsection{Summary}

The main limitation and uncertainty of the study is the composition of the gas may change during the life of the well. This was not evaluated in this study. However, in this analysis a wide range of gas sample were captured and most of the sample had greater than $90 \%$ methane. For these samples, no significant change is expected.

\section{CONCLUSIONS}

(1) Generally the higher the methane percentage in the gas sample the higher the hydrate formation pressure at a fixed temperature.

(2) Generally the higher the propane concentration in the natural gas, the lower the hydrate formation pressure at a fixed temperature.

(3) Impurities affect the hydrate formation pressure/ temperature equilibrium line. Carbon dioxide and Hydrogen sulfide reduces the pressure/temperature equilibrium while nitrogen increases it.

(4) The range of hydrate storage capacities obtained in this analysis was 147-172 scf in $1 \mathrm{cf}$ of gas. The values were consistent with the literature values of $150-180 \mathrm{scf}$ in cf of hydrate. The sample with the higher methane content (dry gas sample) give the higher storage capacity range of 166-172, while the sample with the lower methane content (sample 11) give a storage capacity range of $153-163$ for temperatures $35,40,45$ and $50^{\circ} \mathrm{F}$.

(5) The mole ratio (hydrate number) is approximately 6; however, the actual hydrate number depends on the composition, temperature and pressure. The $\mathrm{V}_{\mathrm{GAS}} /$ $\left(\mathrm{V}_{\mathrm{GAS}}+\mathrm{V}_{\mathrm{HYD}}\right)$ ratio is a useful ratio to illustrate the gradual reduction in free gas (forming the hydrate) as mole ratio, temperature and pressure changes.

(6) To obtain $100 \%$ volume of hydrate, there is a tradeoff between addition water and increasing pressure. In this case, it was a compromise between an additional 119 psia and $68 \mathrm{bbls} / \mathrm{d}$ of water for transporting $5 \mathrm{MMSCF} / \mathrm{D}$. In this case, the additional pressure represents compression work done on the system (approximately $720811 \mathrm{Btu}$ ).

\section{REFERENCES}

[1] Ministry of Energy and Energy, Trinidad (2007). Resource Management Report.

[2] Calsep (2008). PVTSim Software (18th ed.).

[3] Masoudi, R., \& Tohidi, B. (2005). Gas Hydrate Production Technology for Natural Gas Storage and Transportation and $\mathrm{CO}_{2}$ Sequestration. In Proceedings of the SPE Middle East Oil \& Gas Show and Conference, Bahrain, 12-15 March 2005.

[4] Gudmundsson, J., Andersson, V., Levik, O., \& Parlaktuna, M.H. (1998). Concept for Capturing Associated Gas. In Proceedings of the SPE European Petroleum Conference held in Hague, Netherlands, 20-22 October 1998.

[5] Gudmundsson, J., Parlaktuna, M., \& Khokhar, A.A. (1994) Storing Natural Gas as a Frozen Hydrate. SPE Production \& Facilities, 9(1), 69-73.

[6] Makogon, Y., \& Holditch, S. (2002). Gas Hydrate as a Resource and a Mechanism for Transmission. In Proceedings of the SPE Annual Technical Conference and Exhibition, San Antonio, Texas, 29 September-2 October 2002.

[7] Makogon, Y. (1981). Hydrates of Natural Gas. Tulsa: Penn Well Pub. Co.

[8] Makogon, Y. (1997). Hydrates of Hydrocarbon. Tulsa: Penn Well Pub. Co.

[9] Sloan, E.D. (1997). Clathrate Hydrate of Natural Gas. New York: Marcel Dekker.

[10] Okutani, K., Kuwabara, Y., \& Mori, Y. (2008). Surfactant Effects on Hydrate Formation in an Unstirred Gas/Liquid System: An Experimental Study Using Methane and Sodium Alkyl Sulfates. Chemical Engineering Science, 63, 183-194. 